\title{
Specific Features of the Motor Potentials of the Leg Muscles Induced by Magnetic Stimulation under the Conditions of a Five-Day "Dry" Immersion in Healthy Volunteers
}

\author{
I. N. Nosikova ${ }^{a, *}$, A. M. Ryabova ${ }^{a}$, L. E. Dmitrieva ${ }^{a}$, A. Z. Zakirova ${ }^{a}$, V. V. Kitov ${ }^{a}$, \\ E. S. Tomilovskaya ${ }^{a}$, and I. B. Kozlovskaya ${ }^{a}{ }^{\dagger}$ \\ ${ }^{a}$ Institute of Biomedical Problems, Russian Academy of Sciences, Moscow, 123007 Russia \\ *e-mail: nosikovainna@mail.ru \\ Received December 21, 2020; revised January 20, 2021; accepted February 9, 2021
}

\begin{abstract}
The aim of this study was to analyze the mechanisms of the development of hypogravitational hyperreflexia in the motoneuron pool of gravity-dependent muscles such as the gastrocnemius and soleus muscles of the leg under the conditions of five-day "dry" immersion in healthy volunteers using the method of transcranial and trans-spinal magnetic stimulation. The essence of the method lies in the stimulation of the areas of interest (motor areas of the cerebral cortex and lumbosacral thickening) with an electromagnetic stimulus. The study involved 10 subjects at the age of $29.9 \pm 6.9$ years, with no history of movement disorders or neurological diseases. The excitability of the motor neuron pool in both muscles was judged by the values of the thresholds and amplitudes of the motor response caused by transcranial and trans-spinal magnetic stimulations. A general pattern manifested in a significant decrease in thresholds and an increase in the amplitudes of motor responses caused by trans-spinal magnetic stimulation in both muscles gas been discovered. Specifically, the threshold of spinal evoked motor responses in both muscles decreased by $20 \%$, and the amplitude increased by $150 \%$ after the end of immersion. The data obtained during the experiment confirm the spinal nature of the origin of hypogravitational hyperreflexia.
\end{abstract}

Keywords: hypogravity, trans-spinal and transcranial magnetic stimulation, "dry" immersion

DOI: $10.1134 / \mathrm{S} 0362119721030130$

In studies carried out during and after the completion of space flights (SF) [1-4], as well as in experiments simulating the effects of weightlessness on Earth [5-10], and in experiments on animals [11-14], it has been shown that that a decrease in the gravitational load is naturally accompanied by disturbances in the activity of all components and structures of the locomotor apparatus, which together make up the picture of the syndrome of "gravitational ataxia" and "hypogravitational muscle detraining" [15-18]. According to the literature, the rapid development of atony, ataxia, a decrease in the speed-strength properties of muscles and other components of the "motor syndrome" during the transition to microgravity also testifies to its reflex nature [16]. Indeed, the picture of both syndromes includes hyperreflexia of tendon reflexes, manifested by a pronounced decrease in the thresholds of spinal reflex reactions of the extensor muscles of the leg and thigh, in particular $H$ and $T$-reflexes $[5,6,19]$.

The mechanisms of development of hypogravitational hyperreflexia are still the subject of discussion at

\footnotetext{
${ }^{\dagger}$ Deceased.
}

the present time. Various works describe the general pattern of a decrease in reflex thresholds after being in an unsupported environment [5-8, 12, 19]; however, changes in the amplitude of these reflex responses under microgravity and Earth conditions are ambiguous. While during a seven-day SF, as well as in the first week of prolonged SF, there is a decrease in amplitudes of $T$ - and $H$-reflexes [20,21], the changes in the amplitude of the tendon reflex after the mission are multidirectional [20, 22]. Multidirectional changes in the amplitude of muscle responses have also been shown in studies on animals [11, 14].

It can be assumed that the tendency to a decrease in the amplitude of reflex responses is the result of the influence of a peripheral factor, namely, pronounced muscle atony $[2,6]$. Some authors explain the increase in the reflex excitability of motor neurons in the soleus and gastrocnemius muscles of rats during gravitational unloading by a decrease in the size of the neuron soma and a transformation of the level of presynaptic inhibition [12] or the development of so-called denervationlike supersensitivity, which causes an increase in reflex activity [14]. 

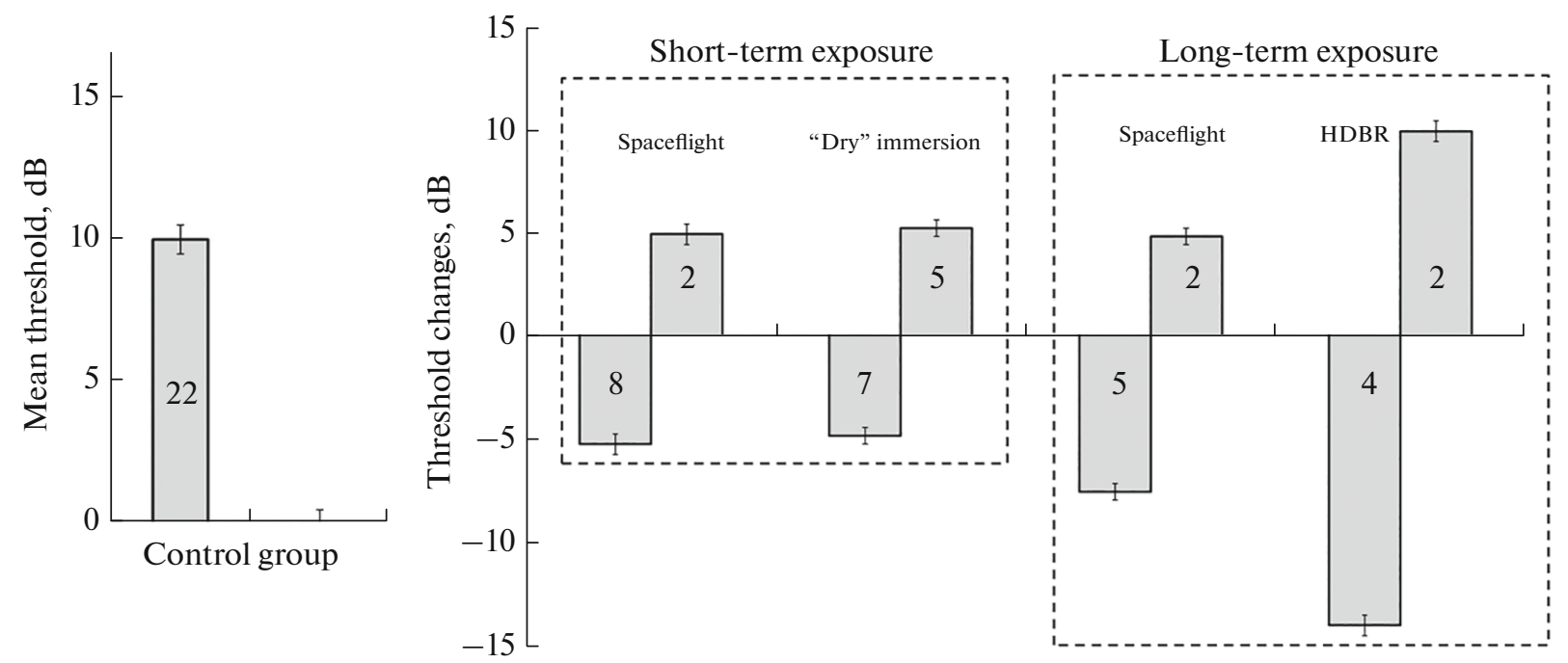

Fig. 1. Changes in vibration sensitivity thresholds after short and long exposure to hypogravity and its models. The right side of the graph shows the mean of the change in decibels: the standard error is indicated by the vertical lines. The numbers inside the columns show the number of cases in the groups. The initial value of the vibration sensitivity threshold is shown in the graph on the left. Adapted from [18].

Analyzing these data, we can conclude that a decrease in amplitude is possible but not necessary for a state of hypogravitational hyperreflexia, while a decrease in thresholds can be considered a characteristic feature of this phenomenon. This fact was confirmed by the results of post-flight examinations of the members of the Salyut-6 mission and model experiments, such as dry immersion (DI) and head-down tilt bed rest (HDBR) [18].

The same studies showed a distinct decrease in vibration sensitivity thresholds in eight out of ten cosmonauts after a short SF (Fig. 1). A similar dynamics of changes was observed in healthy volunteers after DI and HDBR.

Under terrestrial conditions, in $50-80 \%$ of healthy subjects, involuntary movements of the lower extremities can be forcibly evoked by means of vibration stimuli, percutaneous stimulation of the spinal cord, and mechanical stimulation of the supporting zones of the feet [23-26]. It was previously shown that the interneurons of the L7-S1 segments of the spinal cord, which have inputs from muscle afferents, are activated in different ways by the dorsolateral descending system, which ensures the coordinated work of antagonist muscles during the locomotor cycle [27].

In "acute" experiments on cats, it was found that with the help of epidural stimulation of the segments of the lumbar thickening it is possible to induce locomotor activity in intact and to varying degrees devoid of supraspinal influences (decerebrated and spinal) cats. The difference in the induction of locomotor movements in different drugs was that in a series of intact, decerebrated, and spinal animals, an increasing increase in the stimulation frequency (from 5 to
$100 \mathrm{~Hz}$ ) was required to induce locomotion. Studies on decerebrated animals have shown that the morphological substrate of generators of locomotor movements is probably localized in the L4-L7 segments of the spinal cord [28].

The presence of distinctly and reliably manifested changes in different directions after prolonged SF and model conditions indicates the possibility of the existence of a complex of factors that ultimately determine the studied characteristics of evoked motor responses (EMRs), such as the threshold and amplitude of the EMRs. These factors include (a) the initial (background) amplitude of the reflex, changed by the specific activity of the cosmonaut on the day of the preflight examination; (b) the level and types of preventive loads used by the cosmonaut during the flight [29, 30]; (c) the state of the muscular apparatus (i.e., the severity or, conversely, the absence of atrophy) [31, 32]; and (d) the mode of activity of the astronaut after the flight, which determines the individual characteristics of the development of readaptive processes [33].

Thus, it seems important to study the features of the excitability of the spinal and cortico-spinal tracts in a more rigorous model of the altered gravitational environment, since this will allow us to understand their possible role in the development of motor disorders in microgravity.

The purpose of the present study was to estimate the contribution of the spinal and supraspinal structures to the development of hyperreflexia caused by support unloading under DI conditions for five days. 
Transcranial magnetic stimulation

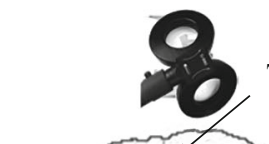

Tical neuron

Trans-spinal magnetic stimulation

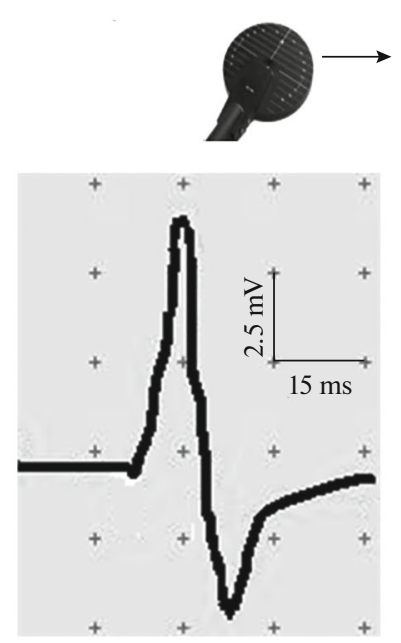

EMR of $m$. soleus

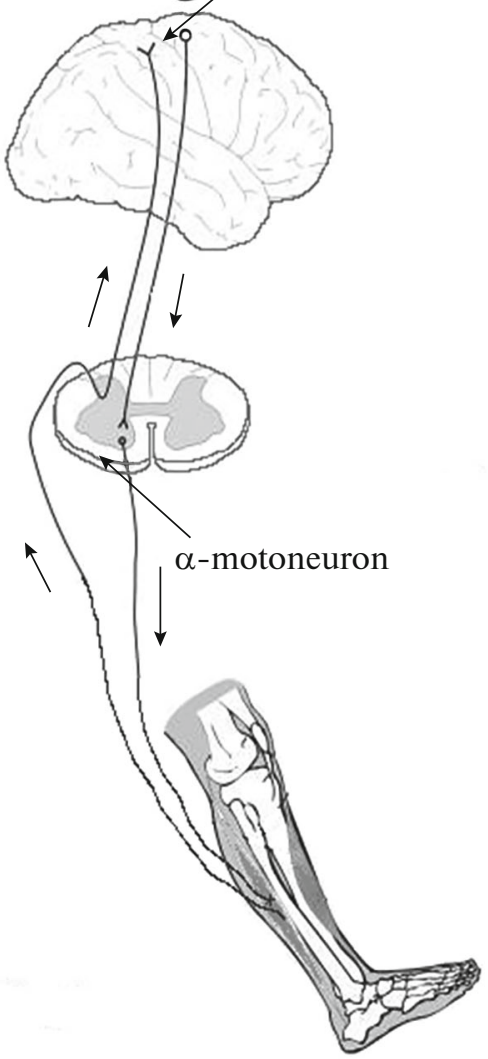

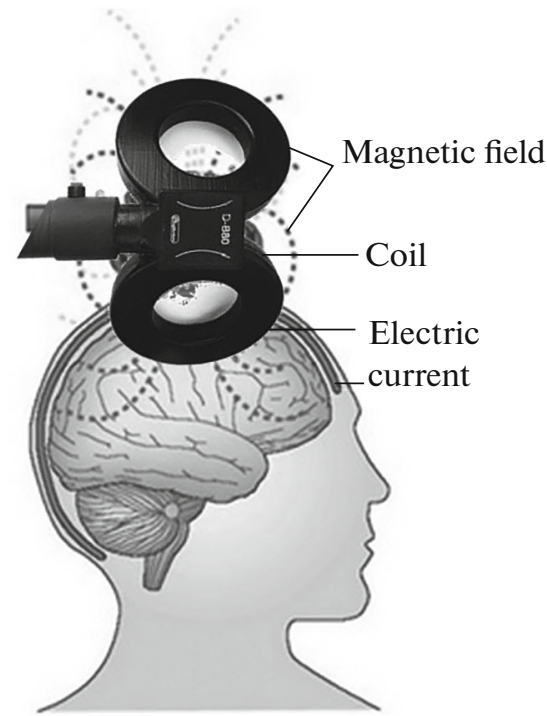

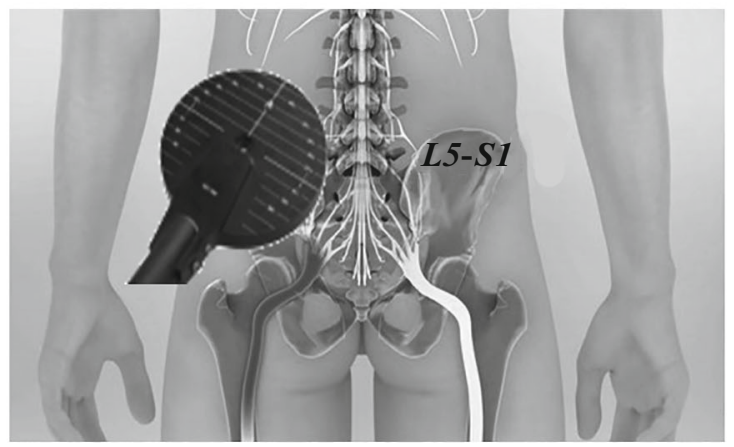

Fig. 2. Scheme of the protocol for recording evoked motor responses to transcranial and trans-spinal magnetic stimulation. The position of the magnetic stimulator coil during transcranial and trans-spinal magnetic stimulation is shown. Adapted from [34].

\section{METHODS}

Ten subjects (aged 29.9 \pm 6.9 years) with no history of movement disorders or neurological diseases took part in the experiments. The subjects during the study lay on a medical couch, face down, in a relaxed state with the eyes open. On the day before the study, the intake of alcoholic and tonic drinks was excluded. A roller was placed under both legs in the ankle area for the best relaxation. During the experiment, motor responses of $\mathrm{m}$. soleus of the right leg to transcranial and trans-spinal magnetic stimulation (MS) were recorded (Fig. 2). To simulate the effects of a short SF, the DI method was used, which accurately reproduced the physiological effects of supportlessness inherent in real weightlessness [35].

Discrete magnetic stimulation of the projection of the soleus muscle of the right leg in the contralateral motor cortex of the brain was performed using an 8-shaped ("butterfly") coil (DB-80 Butterfly) of the MagPro X100 magnetic stimulator (Medtronic, Denmark). The magnetic stimulator is a powerful highvoltage capacitor (from $400 \mathrm{~V}$ to $5 \mathrm{kV}$ ), charged with a high electric current (up to $20 \mathrm{kA}$ ) to the required volt- age. The diameter of the stimulation inductor (coil) was $2 \times 95 \mathrm{~mm}$, the angle between the rings was $120^{\circ}$, the maximum output of the magnetic field on the surface of the coil was $31 \mathrm{kT} / \mathrm{s}$. The maximum inductor power was 350 pulses without stimulation artifacts. The pulse duration was $280 \mu \mathrm{s}$. The coil was placed $1-$ $2 \mathrm{~cm}$ to the left of the point of intersection of the vertex and the line connecting the external auditory canals, gradually determining its position at which the evoked motor responses of $\mathrm{m}$. soleus to transcranial magnetic stimulation (cranial EMR) had the greatest amplitude and constant shape (Fig. 2). Spinal MS was performed using a flat round coil with an outer diameter of $114 \mathrm{~mm}$ and a maximum magnetic field output of $41 \mathrm{kT} / \mathrm{s}$, which was located at the level of the L5-S1 segments of the spine (Fig. 2). With the correct choice of the stimulation zone, the amplitude of the segmental responses was, as a rule, stable. The response with the maximum amplitude was the desired reflex response triggered by magnetic stimulation of the dorsal roots of the spinal cord. After determining the threshold of the EMR (the smallest stimulation force at which a stable motor response occurred), the stim- 
ulation strength was gradually increased in steps of 5$10 \%$ until the evoked motor responses (spinal EMR) of the maximum amplitude or up to $100 \%$ of the maximum output of the magnetic field were obtained. At each strength of stimulation, at least three EMRs were recorded.

The elicited responses of $\mathrm{m}$. soleus and $\mathrm{m}$. gastrocnemius lat. of the leg were recorded using bipolar cutaneous silver chloride electrodes located in the middle of the projection of the soleus muscle abdomen, with an interelectrode distance of $20 \mathrm{~mm}$, using a Viking Quest four-channel myograph (Viasys, United States) with a bandwidth from 2 to $10 \mathrm{kHz}$. The sensitivity band of the device ranged from $0.1 \mu \mathrm{V}$ to $10 \mathrm{mV}$, and the input noise did not exceed $40 \mu \mathrm{V}$. EMR studies were carried out before the start of immersion, on the day of its completion (immediately after the end of the DI), as well as on the third day of the recovery period.

The absolute values of the thresholds and amplitudes of motor responses obtained in baseline studies before immersion exposure were taken to be $100 \%$. Data analysis was performed using the Statistica 6 software. The differences between the data obtained before and after immersion exposure were assessed using the Wilcoxon test for dependent variables.

\section{RESULTS AND DISCUSSION}

As seen in Fig. 3b, the maximum EMR amplitude for transcranial magnetic stimulation in $\mathrm{m}$. soleus on the day of completion of the DI was significantly higher than the initial values, and it was restored after two days to the background values. Thresholds of cEMR of $\mathrm{m}$. soleus at the same time did not change significantly (Fig. 3a). At the same time, the thresholds of the EMRs for trans-spinal stimulation of $\mathrm{m}$. soleus on the day of the end of the DI were significantly lower than the background values (by 20\%), remaining reduced also on the third day of the recovery period (Fig. 3c). The maximum amplitude of the sEMR of $m$. soleus on the day of completion of DI was 2.5 times higher than the initial values $(p<0.05)$, returning to the background values on the third day after the end of the MI (Fig. 3d).

The EMR parameters in m. gastrocnemius exhibited similar dynamics: the absence of significant changes in the case of transcranial stimulation and a significant decrease in thresholds and an increase in the amplitude in the case of trans-spinal stimulation (Fig. 4).

Thus, the data of this study show that, under the conditions of five-day DI, a general pattern of changes was revealed, which consisted in a significant decrease in the thresholds and an increase in the amplitudes of the sEMRs of the leg muscles after the end of the exposure. After the completion of DI, the threshold of sEMR remained low even on the third day of the recovery period, which indicates the depth of the revealed changes. At the same time, the sEMR amplitude, despite a significant increase by a factor of two immediately on the day of the end of DI, recovered to its initial level during this period. This pattern may have been accounted for by that the speed of the impulse along the nerve fiber was restored faster than the excitability of the nerve cells. At the same time, the thresholds and amplitudes of cEMRs did not exhibit significant changes after DI.

The data obtained are generally consistent with those described earlier, showing, at the same time, that the sEMR threshold is a significant characteristic of changes in motor responses. The significant decrease in the thresholds of EMRs on spinal MS revealed in this study after exposure to unsupported conditions confirms the spinal origin of hypogravitational hyperreflexia. Most researchers studying spinal reflex responses in humans and animals (rats) under SF conditions and under model conditions note a decrease in the threshold of reflex responses and an increase in their amplitude [5-8, 12, 14, 19, 36, 37]. However, facilitation of spinal evoked motor responses under the conditions of seven- to ten-day support unloading was noted earlier by other researchers $[8,20]$.

\section{CONCLUSIONS}

(1) Support unloading for five days is accompanied by an increase in spinal excitability, which manifests itself in a significant decrease in thresholds and an increase in the amplitude of motor responses of the leg muscles to trans-spinal magnetic stimulation.

(2) Significantly less pronounced changes in cortico-spinal excitability are manifested in an increase in the amplitude of evoked responses to transcranial magnetic stimulation, while changes in the thresholds of responses under these conditions are not recorded.

Thus, it was shown that the mechanism of the development of hypogravitational hyperreflexia is of a spinal nature, since it manifests itself, first of all, in the form of a decrease in thresholds and an increase in the amplitudes of sEMRs.

\section{FUNDING}

The study was supported by the Russian Science Foundation grant 19-15-00435.

\section{COMPLIANCE WITH ETHICAL STANDARDS}

All studies were carried out in accordance with the principles of biomedical ethics formulated in the 1964 Declaration of Helsinki and its subsequent updates, and approved by the Commission on Biomedical Ethics of the Institute of Biomedical Problems of the Russian Academy of Sciences (Moscow), minutes No. 370 dated September 15, 2014, No. 401 dated July 15, 2015. 
(a)

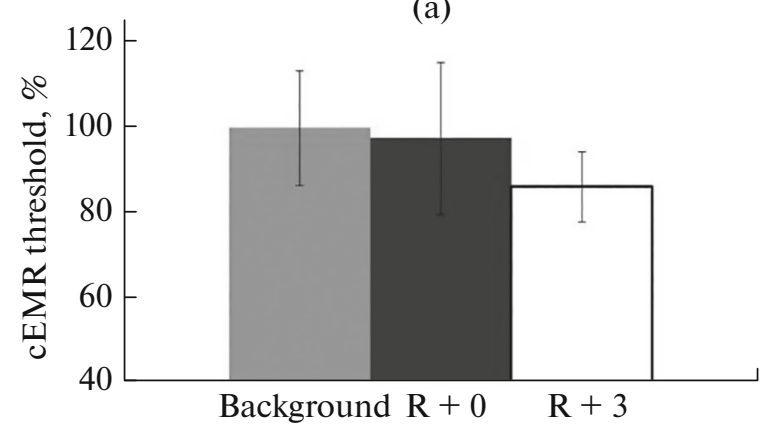

(c)

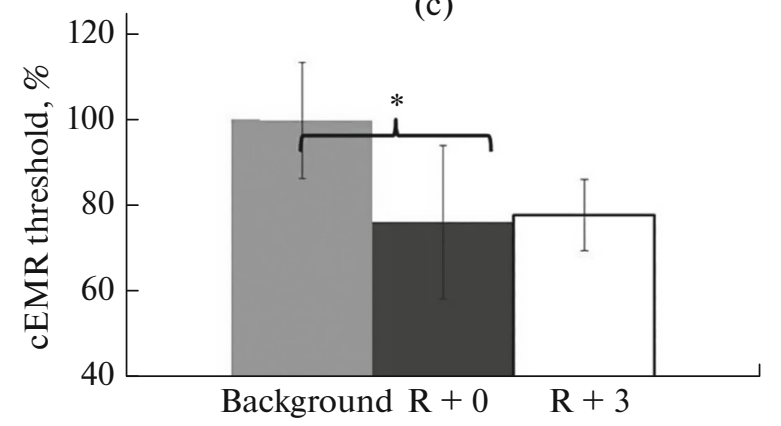

(b)

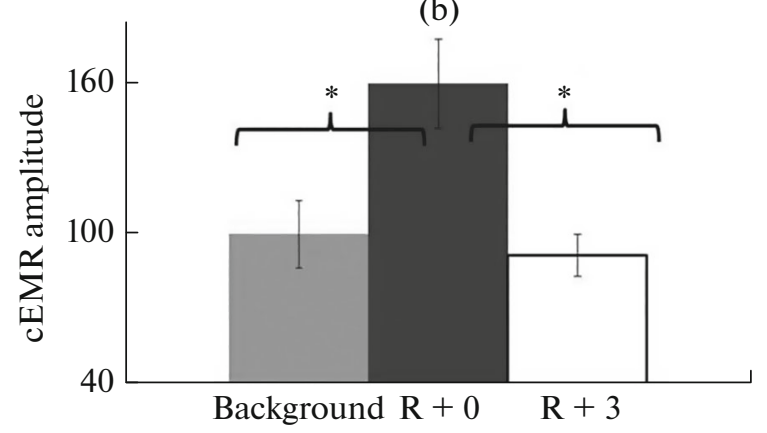

(d)

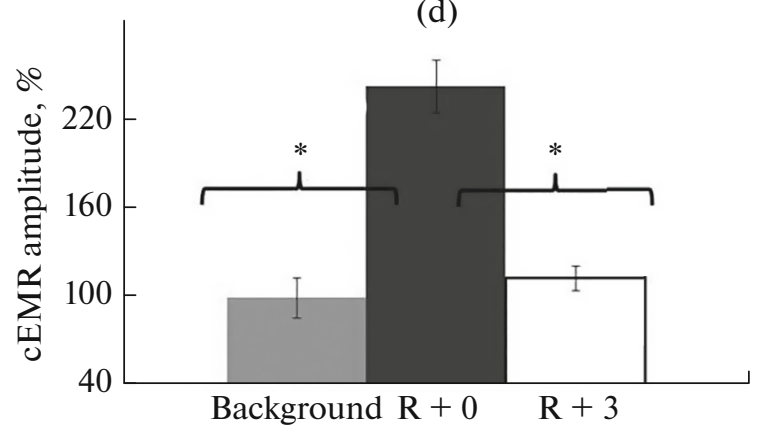

Fig. 3. (a, c) Threshold values and (b, d) amplitudes of evoked motor responses of the m. soleus during transcranial and transspinal magnetic stimulation before the onset of five-day DI and after its completion. * Significant difference from background values, $p<0.05$. Abscissa: background, before immersion; $\mathrm{R}+0$, day of completion of DI ( 30 min after removal from the immersion bath); R + 3, three days after the end of the MI. Ordinate: threshold or amplitude of the EMR, in percent of the initial values.

(a)

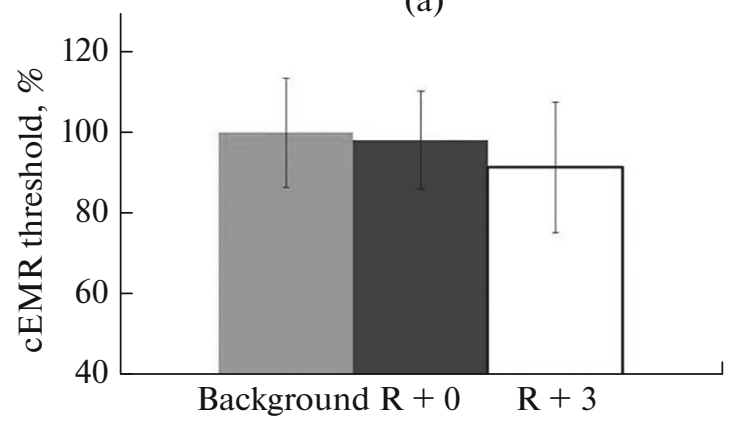

(c)

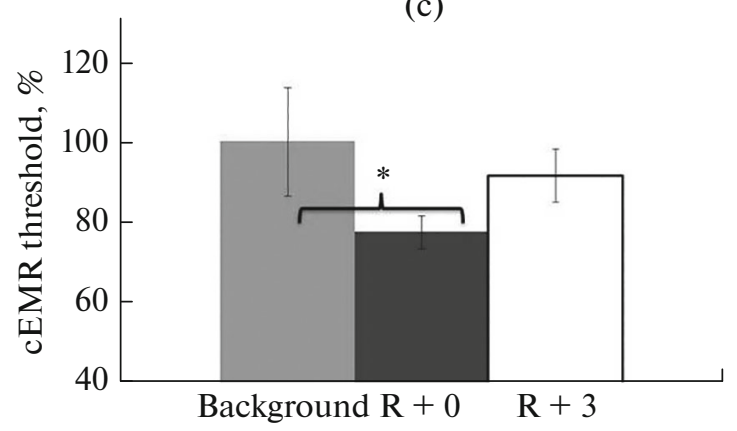

(b)

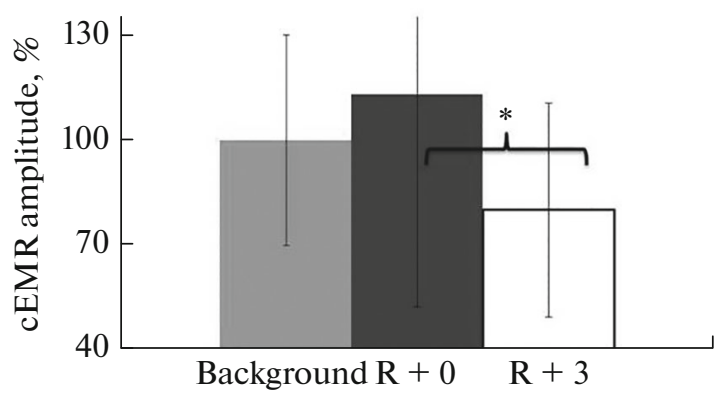

(d)

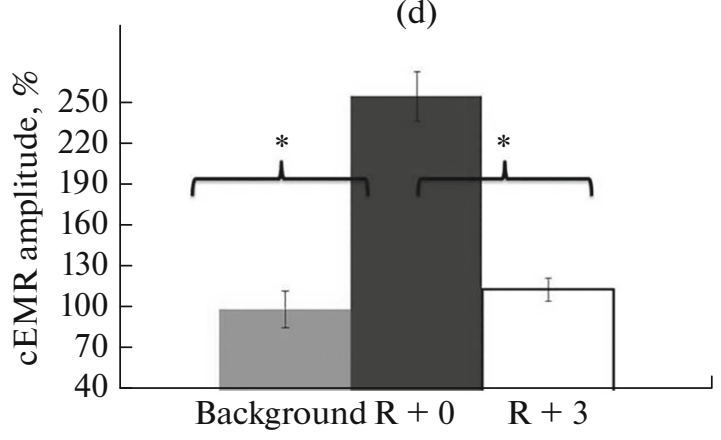

Fig. 4. (a, c) Threshold values and (b, d) amplitudes of evoked motor responses of m. gastrocnemius with transcranial and transspinal magnetic stimulation before the start of five-day DI and after its completion. For designations, see Fig. 3. 


\section{INFORMED CONSENT}

Each study participant provided a voluntary written informed consent, signed by him after explaining the potential risks and benefits, as well as the nature of the upcoming study.

\section{CONFLICT OF INTEREST}

The authors declare no obvious and potential conflicts of interest related to the publication of this article.

\section{OPEN ACCESS}

This article is licensed under a Creative Commons Attribution 4.0 International License, which permits use, sharing, adaptation, distribution and reproduction in any medium or format, as long as you give appropriate credit to the original author(s) and the source, provide a link to the Creative Commons license, and indicate if changes were made. The images or other third party material in this article are included in the article's Creative Commons license, unless indicated otherwise in a credit line to the material. If material is not included in the article's Creative Commons license and your intended use is not permitted by statutory regulation or exceeds the permitted use, you will need to obtain permission directly from the copyright holder. To view a copy of this license, visit http://creativecommons.org/licenses/by/4.0/.

\section{REFERENCES}

1. Reschke, M.F., Anderson, D.J., and Homick, J.L., Vestibulospinal reflexes as a function of microgravity, Science, 1984, vol. 225, no. 4658, p. 212.

2. Kozlovskaya, I.B., Kreidich, Yu.V., Oganov, V.S., and Koserenko, O.P., Pathophysiology of motor functions in prolonged manned space flights, Acta Astronaut., 1981, vol. 8, nos. 9-10, p. 1059.

3. Kornilova, L.N. and Kozlovskaya, I.B., Neurosensory mechanisms of space adaptation syndrome, Hum. Physiol., 2003, vol. 29, no. 5, p. 527.

4. Popov, D.V., Khusnutdinova, D.R., Shenkman, B.S., et al., Dynamics of physical performance during longduration space flight (first results of "Countermeasure" experiment), J. Gravitational Physiol., 2004, vol. 11, no. 2, p. 231.

5. Yamanaka, K., Yamamoto, S., Nakazawa, K., et al., Effects of long-term bed rest on H-reflex and motor evoked potential in lower leg muscles during standing, J. Gravitational Physiol., 1999, vol. 6, no. 1, p. 157.

6. Saenko, I.V., Saenko, D.G., and Kozlovskaya, I.B., Effect of 120 days head-down tilt (HDT) on characteristics of tendinous reflexes, Aviakosm. Ekol. Med., 2000, vol. 34 , no. 4 , p. 13.

7. Davey, N.J., Rawlinson, S.R., Nowicky, A.V., et al., Human corticospinal excitability in microgravity and hypergravity during parabolic flight, Aviat. Space Environ. Med., 2004, vol. 75, no. 4, p. 359.

8. Roberts, D.R., Ricci, R., Funke, F.W., et al., Lower limb immobilization is associated with increased corti- cospinal excitability, Exp. Brain Res., 2007, vol. 181, no. 2 , p. 213.

9. Grigor'eva, L.S. and Kozlovskaya, I.B., Influence of 7day immersion hypokinesia on the characteristics of precise movements, Kosm. Biol. Aviakosm. Med., 1983, vol. 19, no. 4, p. 21.

10. Kirenskaya, A.V., Kozlovskaya, I.B., and Sirota, M.G., Effect of immersion hypokinesia on rhythmic activity of soleus motor units, Hum. Physiol., 1986, vol. 12, no. 4 , p. 275.

11. Kuznetsov, M.V., Baltin, M.E., Fedyanin, A.O., et al., Effect of vibrostimulation of foot and supporting afferentation on functional state of shin muscles in rats during hindlimb unloading, Biophysics (Moscow), 2014, vol. 59, no. 5, p. 806.

12. Eremeev, A.A., Baltina, T.V., Eremeev, A.M., et al., Changes in the functional state of spinal-cord cell structures under gravitational unloading, Biophysics (Moscow), 2016, vol. 61, no. 5, p. 755.

13. Canon, F., Goubel, F., and Guezennec, C.Y., Effects of chronic low frequency stimulation on contractile and elastic properties of hindlimb suspended rat soleus muscle, Eur. J. Appl. Physiol. Occup. Physiol., 1998, vol. 77, nos. 1-2, p. 118.

14. Eremeev, A.A., Chebotarev, M.A., Kuznetsov, M.V., et al., Neuromotor apparatus in the condition of gravitational unloading: central and peripheral effects, Aviakosm. Ekol. Med., 2015, vol. 49, no. 1, p. 32.

15. Kozlovskaya, I.B., Aslanova, I.F., Barmin, V.B., et al., The nature and characteristics of a gravitational ataxia, Physiologist, 1983, vol. 26, no. 6, p. 49.

16. Shenkman, B.S., Grigoriev, A.I., and Kozlovskaya, I.B., Gravity mechanisms in tonic motor system. Neurophysiological and muscle aspects, Hum. Physiol., 2017, vol. 43, no. 5 , p. 578.

17. Paloski, W.H., Black, F.O., Reschke, M.F., and Calkins, D.S., Vestibular ataxia following shuttle flights: effects of microgravity on otolith-mediated sensorimotor control of posture, Am. J. Otol., 1993, vol. 14, no. 1, p. 9.

18. Kozlovskaya, I.B., Dmitrieva, I.L., Grigorieva, L.S., et al., Gravitational mechanisms in the motor system. Studies in real and simulated weightlessness, in Stance and Motion: Facts and Concepts, Gurfinkel, V., Ioffe, M.E., Massion, J., and Roll, J.P., Eds., New York: Springer-Verlag, 1988, p. 37.

19. Lambertz, D., Goubel, F., Kaspranski, R., and Pérot, C., Influence of long-term spaceflight on neuromechanical properties of muscles in humans, J. Appl. Physiol., 2003, vol. 94, no. 2, p. 490.

20. Grigor'ev, A.I. and Ushakov, I.B., Kosmicheskaya meditsina i biologiya (Space Medicine and Biology), Voronezh: Nauchnaya Kniga, 2013.

21. Burlachkova, N.I., Kozlovskaya, I.B., Gurskaya, N.Z., and Markova, E.D., Characteristics of tracking and programmed movements in various disturbances of cerebello-cortical system, in Modern Aspects of Cerebellar Functions, Yerevan: Acad. Sci. Arm. SSR, 1984, p. 374.

22. Saenko, I.V., Characteristics of the activity of spinal mechanisms in conditions of microgravity, Cand. Sci. 
(Med.) Dissertation, Moscow: Inst. Biomed. Probl., Ross. Acad. Sci., 2007.

23. Gerasimenko, Yu.P., Gorodnichev, R., Puhov, A., et al., Initiation and modulation of locomotor circuitry output with multi site transcutaneous electrical stimulation of the spinal cord in non injured humans, J. Neurophysiol., 2015, vol. 113, no. 3, p. 834.

24. Tomilovskaya, E.S., Moshonkina, T.R., Gorodnichev, R.M., et al., Mechanical stimulation of the support zones of soles: the method of noninvasive activation of the stepping movements generators in humans, Hum. Physiol., 2013, vol. 39, no. 5, p. 480.

25. Selionov, V.A., Solopova, I.A., and Zhvansky, D.S., Activation of interlimb interactions increase the motor output in legs of healthy subjects: study under the conditions of arm and leg unloading, Hum. Physiol., 2016, vol. 42, no. 1, p. 43.

26. Shcherbakova, N.A., Moshonkina, T.R., Savohin, A.A., et al., Noninvasive methods to control the human spinal locomotory systems, Hum. Physiol., 2016, vol. 42, no. 1, p. 61.

27. Chen, D., Theiss, R.D., Ebersole, K., et al., Spinal interneurons that receive input from muscle afferents are differentially modulated by dorsolateral descending systems, J. Neurophysiol., 2001, vol. 85, no. 2, p. 1005.

28. Bogacheva, I.N., Kucher, V.I., Shcherbakova, N.A., et al., Mathematical modeling of the mechanisms of locomotory pattern formation under epidural spinal cord stimulation with consideration of peripheral feedback, Biophysics (Moscow), 2005, vol. 50, no. 6, p. 970.

29. Kozlovskaya, I.B., Grigoriev, A.I., and Stepantzov, V.I., Countermeasure of the negative effects of weightlessness on physical systems in long-term space flights, Acta Astronaut., 1995, vol. 36, nos. 8-12, p. 661.

30. Kozlovskaya, I.B., Countermeasures for long-term space flights, lessons learned from the Russian space program, J. Gravitational Physiol., 2002, vol. 9, no. 1, p. 313.

31. Shenkman, B.S., Kozlovskaya, I.B., Nemirovskaya, T.L., and Tcheglova, I.A., Human muscle atrophy in supportlessness: effects of short-term exposure to dry immersion, J. Gravitational Physiol., 1997, vol. 4, no. 2, p. 137.

32. Fitts, R.H., Riley, D.R., and Widrick, J.J., Functional and structural adaptations of skeletal muscle to microgravity, J. Exp. Biol., 2001, vol. 204, no. 18, p. 3201.

33. Kornilova, L.N., Vestibular function and sensory interaction in altered gravity, Adv. Space Biol. Med., 1997, vol. 6, p. 275.

34. Hansen, N.L. and Nielsen, J.B., The effect of transcranial magnetic stimulation and peripheral nerve stimulation on corticomuscular coherence in humans, $J$. Physiol., 2004, vol. 561, no. 1, p. 295.

35. Tomilovskaya, E., Shigueva, T., Sayenko, D., et al., Dry immersion as a ground-based model of microgravity physiological effects, Front. Physiol., 2019, vol. 10, p. 284.

36. Zanette, G., Tinazzi, M., Bonato, C., et al., Reversible changes of motor cortical outputs following immobilization of the upper limb, Electroencephalogr. Clin. Neurophysiol., 1997, vol. 105, no. 4, p. 269.

37. Zanette, G., Manganotti, P., Fiaschi, A., and Tamburin, S., Modulation of motor cortex excitability after upper limb immobilization, Clin. Neurophysiol., 2004, vol. 115 , no. 6 , p. 1264 . 